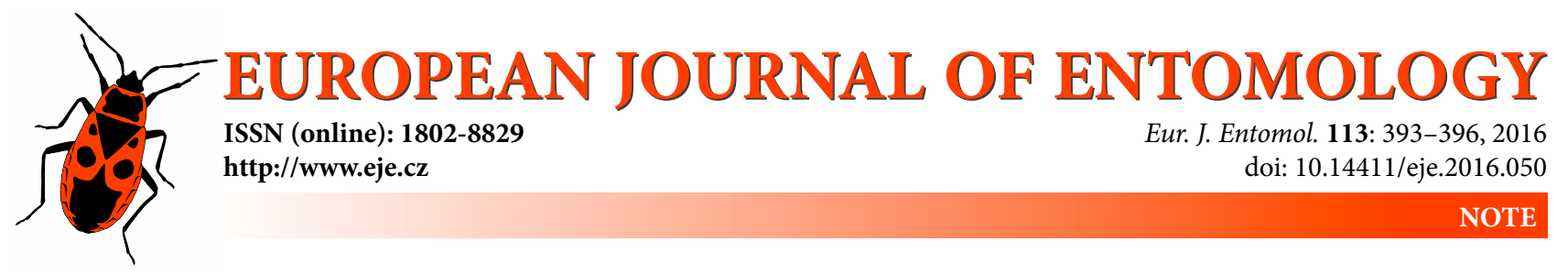

\title{
Infestation of the mycoheterotrophic orchid Yoania japonica by the two-winged fly, Chyliza vittata (Diptera: Psilidae)
}

\section{KENJI SUETSUGU}

Department of Biology, Graduate School of Science, Kobe University, 1-1 Rokkodai, Nada-ku, Kobe, 657-8501, Japan; e-mail: kenji.suetsugu@gmail.com

Key words. Diptera, Psilidae, Chyliza vittata, host plants, mycoheterotrophy, Orchidaceae, Yoania japonica, Gastrodia elata, phytophagous insects, stem-miner

Abstract. Chyliza vittata is known to utilize leaves, stems and underground parts of several leafy and leafless orchids. Compared to the well-recorded feeding habits of $C$. vittata in Europe, its feeding habits in Japan are poorly studied. Thus, further records of its host plants and the habits of its larvae in Japan are likely to reveal the similarities and differences in its feeding habits in Europe and Japan. The current study reports $C$. vittata feeding on the stems of the mycoheterotrophic orchid Yoania japonica in central Japan. This study also showed that in spite of the small size of Yoania its reproductive success is not severely reduced when infested with $C$. vittata, whereas the robust stems of Gastrodia elata, which is its main host plant in Japan, are thought to be a defence against infestation by $C$. vittata.

\section{INTRODUCTION}

The Psilidae is a small family of acalyptrate Diptera in the superfamily Diopsoidea, which includes about 400 described species (Freidberg \& Shatalkin, 2008). The family can be divided into three subfamilies: the Belobackenbardia, Chylizinae and Psilinae (Shatalkin, 2002; Freidberg \& Shatalkin, 2008). The genus Chyli$z a$ is the largest genus in the Psilidae (subfamily Chylizinae) with approximately 120 species (Freidberg \& Shatalkin, 2008). Species of the genus Chyliza are distributed throughout the Afrotropical and Oriental Regions but also to a lesser degree in the Palaearctic Region (Shatalkin, 1997; Freidberg \& Shatalkin, 2008; Bygebjerg et al., 2011; Shatalkin, 2014).

The genus Chyliza includes mainly medium-sized flies, which can be identified by a combination of the following characteristics: head not deltoid in profile, face concave in profile, antenna normal, occiput not swollen, cell cup clearly shorter than cell bm, swelling on anatergite, 6 distinct scutellar bristles, postcoxal bridge well developed, and male genitalia with well-developed surstyli (Iwasa, 1989; Freidberg \& Shatalkin, 2008; Bygebjerg et al., 2011). In common with all members of Psilidae, the larvae of the genus Chyliza are phytophagous (Steyskal, 1987; Iwasa, 1989), feeding on various organs and tissues of plants belonging to at least 10 different families, both angiosperm and gymnosperm (reviewed by Sueyoshi, 2013). For example, the larvae of Chyliza extenuata induce the formation of galls on the stems of holoparasitic plants belonging to the genus Orobanche (Giard, 1900; Chandler, 1975) and the larvae of Chyliza annulipes occur under the bark of Picea and Pinus sp. (Lyneborg, 1987).

Although seven species of Chyliza flies are reported in Japan, ecological data is only available for two species. Larvae of $C$. splendida feed on galls induced by the ampelopsis fruit midge $A s$ phondylia baca Monzen (Cecidomyiidae) in the buds of Weigela floribunda (Caprifoliaceae; Sugiura \& Yamazaki, 2006; Yamazaki \& Sugiura, 2008), while $C$. vittata consumes the leaves, stems and underground structures of several orchid genera, including Gastrodia and Epipactis (Kato et al., 2006; Suetsugu, 2013a; Sugiura, in press). Such interactions between flies and orchids are not unique, with at least five families of Diptera, including the Agromyzidae, Cecidomyiidae, Psilidae, Scathophagidae and Syrphidae known to feed on orchids (Hering, 1957; Sasakawa, 1961; de Jong, 1999; Kato et al., 2006; Uechi et al., 2011). Indeed, some agromyzid and cecidomyiid species are well-known pests of orchids, infesting their flowers and fruits, and causing harmful damage (Hasegawa et al., 1987; Sugiura et al., 1997; Tokuda et al., 2002; Suetsugu 2013b, 2015; Suetsugu \& Fukushima 2014). While the latter three dipteran families are less studied in this context, it is important to understand the interactions between orchids and their feeders, because of the endangered status of most orchids. The current study reports $C$. vittata feeding on the stems of the mycoheterotrophic orchid Yoania japonica in Japan, which was recorded by chance during an investigation of its pollination biology.

\section{MATERIAL AND METHODS}

The field study was carried out in Tateshina city, Kita-Saku county, in the Nagano prefecture of central Japan in mid-June 2012. The study site was in a cool, temperate area at an altitude of approximately $1600 \mathrm{~m}$ in a forested habitat dominated by Betula platyphylla with a sparse cover of understory plants. The $Y$. japonica population at this location was a mixture of the rosy pink flowered form $Y$. japonica f. japonica and the creamy yellow flowered form Y. japonica f. lutea (Suetsugu \& Yagame, 2014), hereafter both of which are simply referred to as Y. japonica. The 

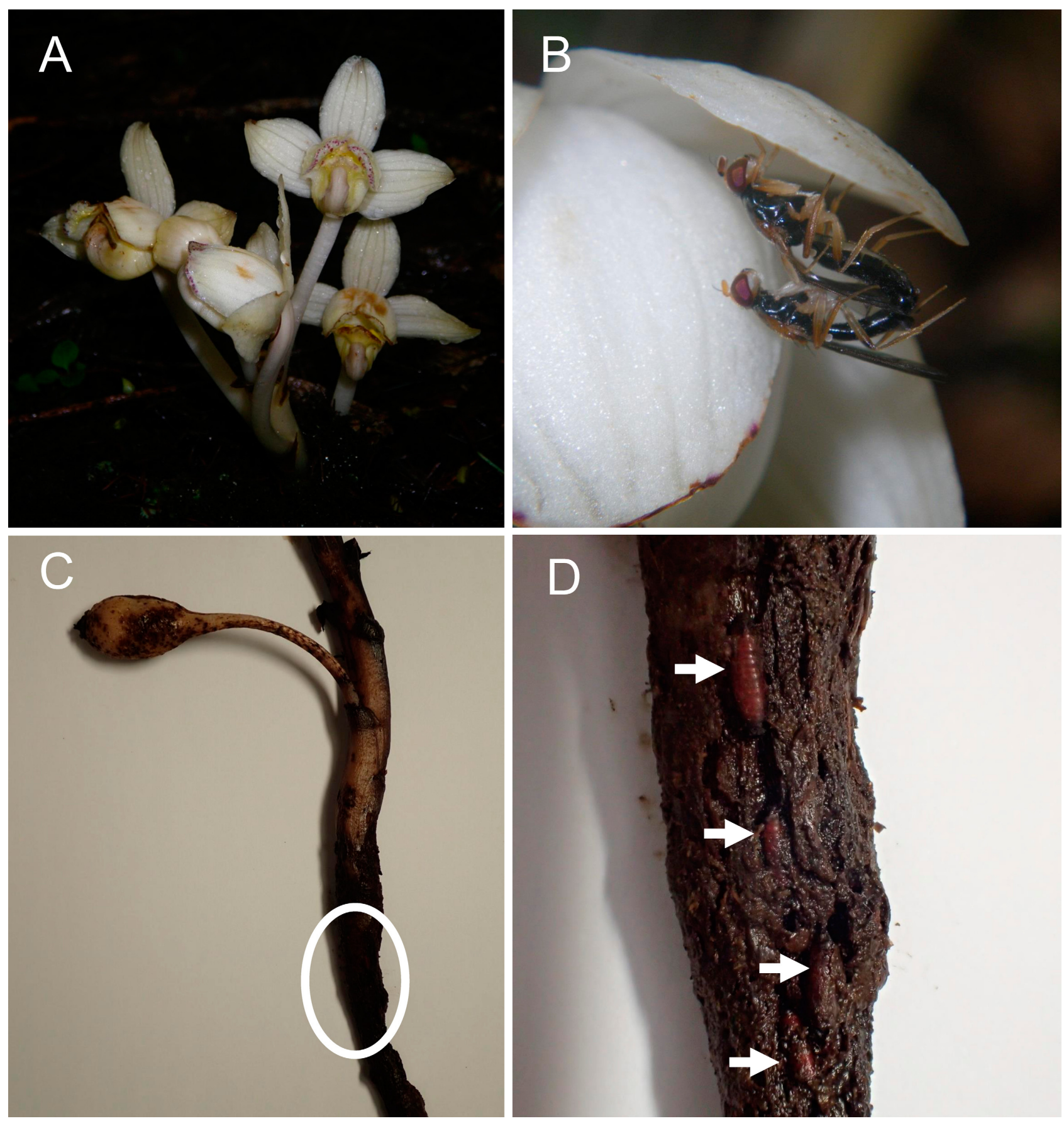

Fig. 1. A - flowering plant of Yoania japonica f. lutea; B - a copulating pair of Chyliza vittata on a flower of Y. japonica; C - fruiting plant of $Y$. japonica whose stem is infested with Chyliza vittata; $D$ - magnification of the enclosed parts of $C$. Puparia in the stem are indicated by arrows.

study site, which was approximately $20 \mathrm{~m}$ by $40 \mathrm{~m}$ in area, contained about 30 flowering plants of Y. japonica. Observations during the 20-h study period were made by walking around the study area or sitting near flowering plants and monitoring the intrafloral behaviour of insect visitors. Floral visitors were carefully observed, with some being captured immediately after they left inflorescences for detailed identification. The study site was revisited in early September 2012, when most of the Y. japonica fruit had matured, to investigate the stems of the $Y$. japonica plants that C. vittata females laid eggs on during the flowering season. Great care was taken when collecting the samples because $Y$. japonica is designated nearly threatened or endangered in 26 of the 47 prefectures in Japan, including Nagano Prefecture, the location of the study site (Association of Wildlife Research \& Envision Conservation Office, 2012). Only three stems were collected and the underground structures of the plants were not excavated in order to minimize any negative effects on the $Y$. japonica population investigated. The stem samples were placed in plastic containers filled with vermiculite and incubated at $15^{\circ} \mathrm{C}$ under wet conditions for ca. 1 month before the temperature was reduced to $5^{\circ} \mathrm{C}$ during the period from October to the following March when they were removed from the incubator and inspected.

\section{RESULTS}

Five males and seven females of $C$. vittata were observed visiting flowers of $Y$. japonica at the study site. The females could eas- 
ily be distinguished from the males because their wings were usually held erect and half-open (Sugiura, in press). The female flies were found on various plant structures and were observed walking between them. In addition, the females were also observed laying eggs on the plant surface, often gradually changing their abdominal position in order to place the eggs on different parts of the flower, including the inner portions of the flower, the outer surface of the sepals and petals, or the pedicels. Food-searching/ feeding behaviour was not recorded for either the males or females, although it was apparent that the plants on which the females laid eggs were used as an encounter site for the males, as is often the case with G. elata (Sugiura, in press). Indeed, males were sometimes observed grasping the females with swollen abdomens after oviposition, during which time copulation occurred (Fig. 1). When the site was revisited during the fruiting season (September), the puparia of $C$. vittata were found just beneath the epidermis of the basal stem (Fig. 1). Even the heavily infested stems of $Y$. japonica were still capable of producing well-developed fruit capsules with numerous viable seeds (Fig. 1). Adult $C$. vittata flies emerged from the pupae in the rotten stems collected the following March, indicating that $C$. vittata overwinters in $Y$. japonica as a puparium.

\section{DISCUSSION}

The present study clearly demonstrates that the mycoheterotrophic orchid Y. japonica is one of the host plants of the larvae of C. vittata. Furthermore, as in G. elata (Sugiura, in press), male $C$. vittata flies exhibited mate seeking behaviour on flowering plants of $Y$. japonica to which females were attracted to lay eggs, which resulted in copulation. These facts indicate that $Y$. japonica can be used as a mating site for $C$. vittata.

Until recently, the only documented host of $C$. vittata in Japan was $G$. elata, of which both the buds and stems can be infested (Kato et al., 2006; Sueyoshi, 2013). However, European populations of $C$. vittata are known to be leaf or stem miners and root borers of at least five genera of European orchids. For example, it is reported that the larvae of $C$. vittata can mine the leaf sheaths and stems of Cephalanthera damasonium, Epipactis helleborine and Epipactis purpurata and pupate in their roots (Pitkin et al., 2012). In addition, the larva of $C$. vittata also tunnel in the tubers of Neottia nidus-avis, and are associated with three other genera, including Dactylorhiza, Himantoglossum and Orchis, although the species of these plants were not identified (de Meijere, 1940; Hering, 1957). With the exception of G. elata, all of the hosts utilized by $C$. vittata have relatively short stems of less than $50 \mathrm{~cm}$ in length. In contrast, the stems of $G$. elata are robust, growing to a height of approximately $1 \mathrm{~m}$, and sometimes as high as $2 \mathrm{~m}$. Such long flower stems are unusual amongst mycoheterotrophic plants and it is suggested by Kato et al. (2006) that the long stems of $G$. elata protect them from infestation by $C$. vittata.

Although the association between G. elata and Japanese populations of $C$. vittata appears to be exceptional compared to those recorded in Europe it is suggested that further research is needed to identify other host plants in Japan in order to determine whether Kato et al.'s (2006) hypothesis is well supported (Sueyoshi, 2013). A recent study by Suetsugu (2013a) indicates that Japanese populations of $C$. vittata utilize other species of hosts, in particular they oviposit in the flowers of E. helleborine var. papillosa. Taken together with the results of the current study, these findings suggest that the association between $C$. vittata and $G$. elata is not specific, even in Japan. In addition, even though the stems of $Y$. japonica are much shorter than those of G. elata, usually being less than $30 \mathrm{~cm}$ (Suetsugu \& Yagame, 2014), it seems that infestation by $C$. vittata does not severely reduce the reproductive success of $Y$. japonica. The infested stems of $Y$. japonica were still capable of producing mature fruit capsules with numerous viable seeds, indicating that the larvae of $C$. vittata mainly consume the pedicels and stems, but not the developing ovaries. Such observations indicate that the robust flower stems of $G$. elata may not be a counter-adaptation to herbivory by $C$. vittata, but may have evolved for another reason, such as increasing pollinator attraction. Further research on the selection of host plants by $C$. vittata in Japan is required to gain a fuller understanding of the similarities and differences between their feeding habits in two geographically disjunct regions: Europe and Japan.

ACKNOWLEDGEMENTS. This study was partly supported by a grant-in-aid by the Japan Society for the Promotion of Science (15K18470).

\section{REFERENCES}

Association of Wildlife Research \& Envision Conservation OfFICE 2012: Search System of Japanese Red Data. URL: http:// www.jpnrdb.com/ (last accessed 18 Apr. 2016).

Bygebjerg R., Munk T. \& Elnif J. 2011: Chyliza leguminicola Melander, 1920 (Diptera: Psilidae) new to the Palaearctic fauna. - Entomol. Meddel. 79: 73-84.

ChANDLER P.J. 1975: Observations on plant associations of the Psilidae (Diptera). — Entomol. Rec. 87: 13-17.

De Jong H. 1999: Family Scathophagidae. In Papp L. \& Darvas B. (eds): Contributions to a Manual of Palaearctic Diptera, Appendix. Science Herald, Budapest, pp. 431-445.

De Meijere J.C.H. 1940: Über die Larven der in Orchideen minierenden Dipteren. - Tijdschr. Entomol. 83: 122-127.

Freidberg A. \& Shatalkin A.I. 2008: The Psilidae (Diptera) of Israel, with emphasis on the Chamaepsila hebracia group. Isr. J. Entomol. 38: 35-60.

IwASA M. 1989: The Japanese species of the genus Chyliza (Diptera, Psilidae). - Jpn. J. Entomol. 57: 148-162.

Giard A. 1900: Sur la biologie de Chyliza vittata Mg. (Dipt.). Bull. Soc. Entomol. Fr. 1900: 316.

Hasegawa H., Nakasugi M. \& Goi M. 1987: A seed harvesting method of Cypripedium japonicum Thunberg. - Tech. Bull. Fac. Agric. Kagawa Univ. 38: 63-70.

HeRING E.M. 1957: Bestimmungstabellen der Blattminen von Europa. W. Junk, Gravenhage, $1185+221$ pp.

Kato M., Tsuji K. \& Kawakita A. 2006: Pollinator and stem- and corm-boring insects associated with mycoheterotrophic orchid Gastrodia elata. - Ann. Entomol. Soc. Am. 99: 851-858.

LyNeborg L. 1987: On the life history of Chyliza annulipes Macquart, 1935 (Diptera: Psilidae). - Entomol. Meddel. 55: 27-29.

Pitkin B., Ellis W., Plant C. \& Edmunds R. 2012: The Leaf and Stem Miners of British Flies and Other Insects. URL: http:// www.ukflymines.co.uk/Flies/Chyliza_vittata.php (last accessed 18 Apr. 2016).

Sasakawa M. 1961: A study of the Japanese Agromyzidae (Diptera) Part III. - Sci. Rep. Kyoto Pref. Univ. Agric. 13: 60-67.

Shatalkin A.I. 1997: Review of the Asian species of Chyliza Fallén (Diptera, Psilidae). - Russ. Entomol. J. 6: 89-111.

Shatalkin A.I. 2002: Afrotropical Psilidae (Diptera). 1. Genera Belobackenbardia gen. n. and Psila Meigen, 1803. - Rus. Entomol. J. 10: 417-424.

Shatalkin A.I. 2014: Chyliza gavryushini sp. n. (Psilidae) and Cypselosoma tibialis sp. n. (Cypselosomatidae) - two new dipterous species from Vietnam. - Russ. Entomol. J. 23: 151154.

Steyskal G.C. 1987: Psilidae. In McAlpine J.F., Peterson B.V., Shewell G.E., Teskey H.J., Vockeroth J.R. \& Wood D.M. (eds): 
Manual of Nearctic Diptera 2. Agriculture Canada, Ottawa pp. 781-784.

Suetsugu K. 2013a: Delayed autonomous self-pollination in two Japanese varieties of Epipactis helleborine (Orchidaceae). Bot. J. Linn. Soc. 173: 733-743.

Suetsugu K. 2013b: Autogamous fruit set in a mycoheterotrophic orchid Cyrtosia septentrionalis. - Plant Syst. Evol. 299: 481-486.

Suetsugu K. 2015: Autonomous self-pollination and insect visitors in partially and fully mycoheterotrophic species of Cymbidium (Orchidaceae). - J. Plant Res. 128: 115-125.

Suetsugu K. \& Fukushima S. 2014: Bee pollination of the endangered orchid Calanthe discolor through a generalized fooddeceptive system. - Plant Syst. Evol. 300: 453-459.

Suetsugu K. \& Yagame T. 2014: Color variation of the mycoheterotrophic Yoania japonica (Orchidaceae) - Acta Phytotax. Geobot. 65: 49-51.

SueYoshi M. 2013: Orchidophaga gastrodiacola Kato, 2006, is Chyliza vittata Meigen, 1826 (Diptera: Psilidae): discussion on its taxonomy and biology. - Zootaxa 3620: 473-480.
Sugiura N. 2016: Bionomic notes on Chyliza vittata (Diptera: Psilidae) infesting the leafless orchid Gastrodia elata. - Entomol. Sci. (in press).

Sugiura S. \& YAmazaKi K. 2006: First record of a psilid fly feeding on cecidomyiid galls. - Can. Entomol. 138: 235-237.

Sugiura N., Okajima Y. \& Maeta Y. 1997: A note on the pollination of Oreorchis patens (Orchidaceae). - Ann. Tsukuba Bot. Garden 16: 69-74.

Tokuda M., Yukawa J., Yasuda K. \& Iwaizumi R. 2002: Occurrence of Contarinia maculipennis (Diptera: Cecidomyiidae) infesting flower buds of Dendrobium phalaenopsis (Orchidaceae) in greenhouses on Okinawa Island, Japan. - Appl. Entomol. Zool. 37: 583-587.

Uechi N., Yukawa J., Tokuda M., Ganaha-Kikumura T. \& TaniGUCHI M. 2011: New information on host plants and distribution ranges of an invasive gall midge, Contarinia maculipennis (Diptera: Cecidomyiidae), and its congeners in Japan. - Appl. Entomol. Zool. 46: 383-390.

YAMAZAKI K. \& SUgiURA S. 2008: Arthropods associated with bacterium galls on wisteria. - Appl. Entomol. Zool. 43: 191-196.

Received March 21, 2016; revised and accepted April 19, 2016 Published online May 3, 2016 